\title{
Impact of Print Media on Student's Academic Performance of Varanasi City, India
}

\author{
Salem Aboglila* \\ Department of Geochemistry \& Environmental Chemistry, Assistant Professor, Azzaytuna University, Libya
}

*Corresponding author: Salem Aboglila, Department of Geochemistry \& Environmental Chemistry, Assistant Professor, Azzaytuna University, Libya

\begin{tabular}{|c|c|}
\hline ARTICLE INFO & ABSTRACT \\
\hline Received: 幽 February 01, 2021 & $\begin{array}{l}\text { The print media have assumed an essential role in our students' daily lives. Print } \\
\text { media has demonstrated an intense effect on students/school-going children. Print media }\end{array}$ \\
\hline Published: 櫘 February 16, 2021 & \\
\hline $\begin{array}{l}\text { Citation: Salem Aboglila. Impact of Print } \\
\text { Media on Student's Academic Performance } \\
\text { of Varanasi City, India. Biomed J Sci \& Tech } \\
\text { Res 33(5)-2021. BJSTR. MS.ID.005478. }\end{array}$ & $\begin{array}{l}\text { selected from two different (one public and one private) schools of Varanasi city using a } \\
\text { self-structured questionnaire as a tool for obtaining data while frequencies distribution } \\
\text { and percentages of data were conducted to know comprehensively about data. It targeted } \\
120 \text { students between } 11 \text { to } 19 \text { years age group and find out that the print media helpful } \\
\text { for their academic performance and the study also recorded the student's subject stream, }\end{array}$ \\
\hline $\begin{array}{l}\text { Keywords: Print Media; Students; } \\
\text { Academic Performance; Public School; } \\
\text { Private School }\end{array}$ & $\begin{array}{l}\text { access print media sources, helpful in their academic achievements, encourage students } \\
\text { to do something new, innovative, creative and different with their academic projects and } \\
\text { assignments and got help from the print media sources. The result of the study revealed } \\
\text { that cent percent of the selected students' for the study were accessed print media } \\
\text { sources by both public and private schools students. The majority of the students from } \\
\text { both schools were encouraged by print media to do new and innovative things with their } \\
\text { academic projects and assignments and also the majority of the student stated that print } \\
\text { media sources were helpful in their academic performance in most of the cases. So, it } \\
\text { was concluded from this study that printed sources are still prefered first in compare } \\
\text { comparison to electronic mediums. Print media sources are useful in their academics } \\
\text { because it covers so many educational and informative issues. }\end{array}$ \\
\hline
\end{tabular}

\section{Introduction}

Today, in this modern and technological world, the role of mass media or particularly of print media has been expanding day by day. Due to technological changes, there have been drastic changes in all sectors as well as in the educational industry. It has rapid changes in the field of educational industry [1]. The print media has been largely responsible for running educational campaign for everyone including school going children. Not only pieces of information or news are conveyed to readers, experts from almost all the major fields of life, education, medicine, environment, economists and religious scholars write in the print media. This is an enormous thing to be done by the media. Print Media has also created awareness among the people regarding their rights and duties [2]. Print media sources are a powerful medium of mass media; it has always been serving the people of India. Print media sources are conveying information due to cheap medium, easy accessibility, easily stored and also extended reach as well as high frequency of publication. These are archives, objects of records and can be referred to, checked again and leave a long impact. Also, the print mediums have power to describe the events at greater length whereas other mediums have limitations [3]. For example, it plays a major role in increasing positivity in children's development in various educational information and various aspects of future career which may serve to increase children's or students' knowledge and understanding of various life aspects. Since this is a time of exploration and change, individuals may seek (Arnett,2000). Everyone from child to an old man gets a lot of information through different media i.e. newspaper, TV, radio, magazines, journals, films, etc.

It is estimated that mass media may substitute the real classroom teaching in the future. John Dewey stated that education could not be limited within teacher and taught without social environment. Print media sources provide lasting experience 
rather than instant entertainment, education and information but also uphold cultural value in individuals. Electronic media sometimes has inbuilt information hierarchies which, at times, affect ease of use. In addition, print sources have much less health hazards than electronic sources. But many attributes like ubiquity, quality of display, ease and speed of browsing and aesthetics like feel, texture, quality of binding, etc. of a printed book still score high than electronic media [4]. The print media sources publish certain articles/issues of interest related to the adolescents that's why they get encouraged into the habit of using it. Other than educational issues like how to deal with stress, loneliness, peer pressure, substance abuse learn about their interest (some creative activity, gardening, games) etc. also be a apart from other health issues like obesity, diabetes and other lifestyle-related diseases, which strikes people at a very young age now. Child abuse especially of the girl child is still prevalent in spite of stringent laws; the newspaper also creates awareness about how to deal with these issues. Most of the news related to such thing is about an event and the punishment given to the perpetrator but no concrete step is taken to create awareness and also prevention of such activities [5].

\section{Role of Print Media}

Print media is used as a powerful information tool worldwide that helps to increases children's literacy by using the print media sources as a teaching tool for them [6]. Print media sources uses in a unique way that helps to motivate and teach students with a textbook as fresh as each day's news. It also stated that through the use of daily news, editorial, features and even advertising, students at all grade levels can learn math and cost comparison skills, geography and meteorology, history and current issues and how they shape our world, all while improving reading habits, comprehension meaning of different words improve it [7]. The media has also been targeting adolescence to capture their consumers of the future. A number of studies in the late nineties have focussed on the effect of television and other media on adolescent 's health and behaviour, especially the effect of television on children, the effect of films on violent behaviour and the likes [8]. The learners not only improve their reporting skills but also enrich new vocabulary, reading comprehension skills, particularly, skimming, scanning, vocabulary, comprehension skills [9]. So as children grow up in a society full of these mediums of print media they are not immune to both the positive and negative effects of the media. Whereas the media has evolved from a vital entertainment and information tool, it has equally had great impact in education [10].

Newspapers educate the people including students on political, social, economic and cultural developments. In addition to the routine publication, in recent times, English and regional dailies are bringing out Educational supplements on weekly basis. In-depth articles on challenges of education, innovation in the educational sector, experiments in the teaching-learning process find a place in the supplements. This is a boon for the students to refresh their school teaching and improve upon their own understanding of studies. In a bid to bring students to the reading (Table 1) and to cultivate the habit of reading, newspapers are publishing and supplying additional supplements to the schools in targeted areas so as to wean their attention on the core issue of education. Thus, newspapers are providing formal and informal education. An increasing number of violent acts to and from the young children cries out for a suitable solution urgently. Students are very clear about what they want and choose what they want for it. These print media sources are very helpful. Hence this study was an attempt to know about the access print media sources by students of Varanasi city and helpful in their academic performance.

Table 1: Distribution of students of both schools according to access of print media.

\begin{tabular}{|c|c|c|}
\hline \multirow{2}{*}{ Access Print Media } & Public School & Private School \\
\cline { 2 - 3 } & $\mathbf{f}(\mathbf{\%})$ & $\mathbf{f}(\mathbf{\%})$ \\
\hline Yes & $60(100)$ & $60(100)$ \\
\hline No & - & - \\
\hline
\end{tabular}

\section{Materials and Method}

Method of the study plays an important role in every study. This study has used the survey method to collect data. This study has adopted a descriptive research design, which includes stream of the students and print media encourage students to do something new and it is also helpful in their academic performance of both (public and private) school students. Sample for this study was selected among the students of regular school going students of Varanasi city. The sample also comprised public and private school students. Samples were drawn from different type of schools like public school (Smt. Pyari Singh Intermediate School) and private school (Little Flower School). Total numbers of respondents whose responses were taken up for analysis was 120 school going students. Data were gathered using a self-structured questionnaire prepared specially for this study. The variables used in the study related to print media. The frequency and simple percentage used for the analysis of this study.

\section{Results and Discussion}

The ensuing part of the article presents the stream of the students, access print media, encourage students to do something new, innovative and different and helpful in their academic achievements. Data was presented in form of tables, percentages and bar graphs.

a) Stream of students: For this present study students were selected from two different schools (public and private school) and different streams i.e. Biology, maths and commerce. (Table 2) reveals that there are majority of students were belongs to mathematics stream in private school whereas in public school majority of students were belongs to biology stream while in private school less than half of selected (43.33\%) students belonged to biology. Data also revealed that 31.66 percent students were adopted mathematics and rest of the students i.e. (15.26\%) 
were adopted commerce in public school while in private school no one was adopted commerce stream.

Table 2: Distribution of students according to different subject streams.

\begin{tabular}{|c|c|c|}
\hline \multirow{2}{*}{ Stream (N=120) } & Public School & Private School \\
\cline { 2 - 3 } & $\mathrm{f}(\%)$ & $\mathrm{f}(\%)$ \\
\hline Biology & $30(50.00)$ & $26(43.33)$ \\
\hline Mathematics & $19(31.66)$ & $34(56.66)$ \\
\hline Commerce & $11(15.26)$ & - \\
\hline
\end{tabular}

b) Access print media: No one is untouched by the use of print media. It is going to happen to us every day like we all start our day with a newspaper. Can you imagine a world without paper? Nowadays paper has become an integral part of our life. We read papers in the morning, write on note books made of paper, send letters on paper, use paper boxes to carry things and so on [11]. In this present study cent percent of the selected students from both schools were access different sources of print media i.e. newspaper, magazine, science fictions, competitive books, manuals, brochures, literature books and grammar and comprehensive books etc. Figure 1 Above (Table 3) shows that students selected from both school were access the print media sources. Similar results were found by Goswami and Kumari (2013) reported that print media is the largest accepted and used media and $100 \%$ of population uses this. 391 students reads daily newspaper and other print media sources.

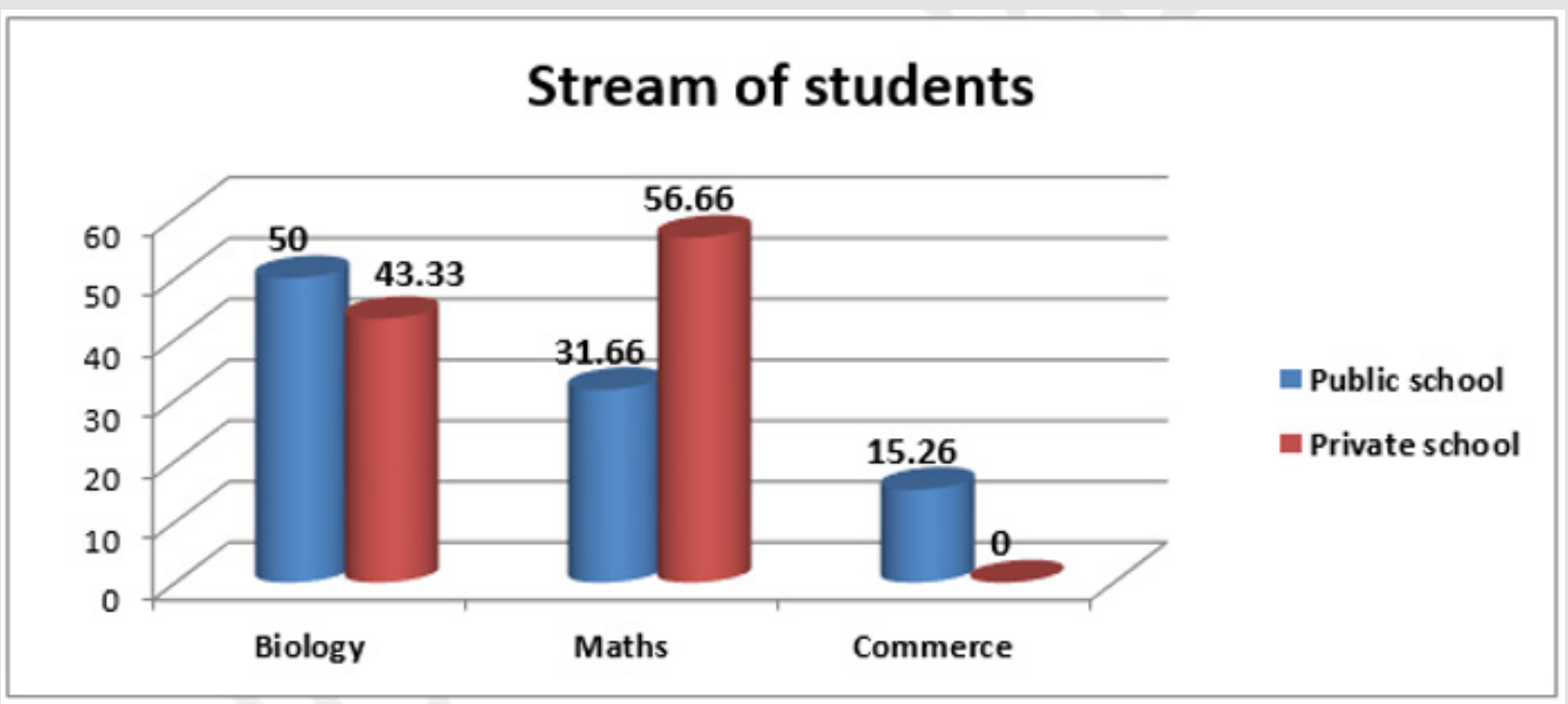

Figure 1: Distribution of students according to different subject streams.

Table 3: Distribution of student's response on the basis of print media encourage them.

\begin{tabular}{|c|c|c|}
\hline \multirow{2}{*}{ Response } & Public School & Private School \\
\cline { 2 - 3 } & $\mathbf{f ( \% )}$ & $\mathbf{f}(\mathbf{\%})$ \\
\hline Yes & $47(78.33)$ & $52(86.66)$ \\
\hline No & $13(21.66)$ & $18(14.33)$ \\
\hline
\end{tabular}

c) Print media encouraging students: Print media sources are the store house of knowledge and provide knowledge of different kinds of segments of the society. It helps to improve communication skill. Reading and use of print media sources fires the imagination of the person. Systematic and regular use of these sources are sharpens the intellect, refines the emotions, elevates tastes and provides perspectives for one's living and thereby prepares a person for and effective participation in the social, religious, cultural and political life. Print sources gave recognition, understanding and comprehension. A comprehension skill helps students understand the meaning of different words in isolation and context. Effective reading is the most important avenue of effective learning for the school going students. Above (Table 2) shows that print media sources encourage students to do something new, innovative, and different with their assignments and projects given in schools. Figure 2 Data presented in (Table 4) also shows that majority (78.33\%) of the selected students from public school stated that print media sources encourage them, and 21.66 percent students were not encourage by print media from public school. In private school 86.66 percent of selected students also stated that sources of print media encouraged them to do new, innovative and different things with their school assignments and projects whereas 14.33 percent students were said that it's not like that. In contrast to result [12]. found that television is the most popular source of information with $78.00 \%$ youth following, relegating newspapers, with a dismal $07.50 \%$ rating, to the 'leisure activity' status. Books, newspapers, and magazines are read as the level of education increases. However, their popularity decreases with age. 


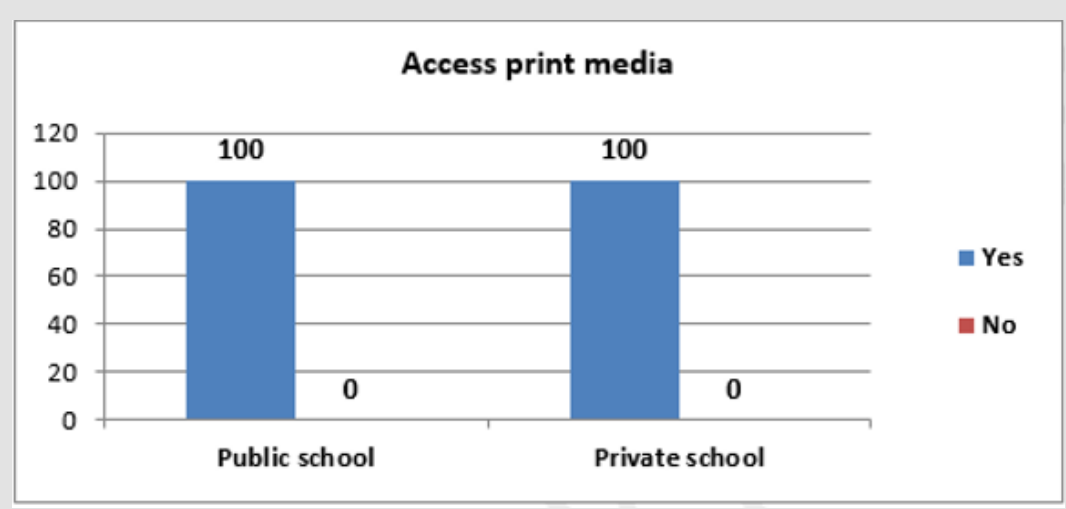

Figure 2: Distribution of students of both schools according to access of print media.

d) Print media sources help you in your academic achievements: In this given (Table 3) data shows that different sources of print media are useful in their academic works. Figure 3 Data presented in (Table 4 ) revealed that 63.33 percent of selected students from public school stated that different sources of print media were helpful in their academic achievements, followed by 20.00 percent students were state that these sources were not helpful and 16.66 percent students were said that sometimes print media sources were helpful while 76.66 percent students from private school stated that print media helpful for their school projects and assignments got from school, 18.33 percent students said that print sources not so helpful although only 05.00 percent students said that sometimes these sources helpful for them Figure 4.

Table 4: Distribution of response of students on sources of print media help in their academic achievements.

\begin{tabular}{|c|c|c|}
\hline \multirow{2}{*}{ Response } & Public School & Private School \\
\cline { 2 - 3 } & $\mathbf{f ~ ( \% )}$ & $\mathbf{f}(\mathbf{\%})$ \\
\hline Yes & $38(63.33)$ & $46(76.66)$ \\
\hline No & $12(20.00)$ & $11(18.33)$ \\
\hline Sometimes & $10(16.66)$ & $3(05.00)$ \\
\hline
\end{tabular}

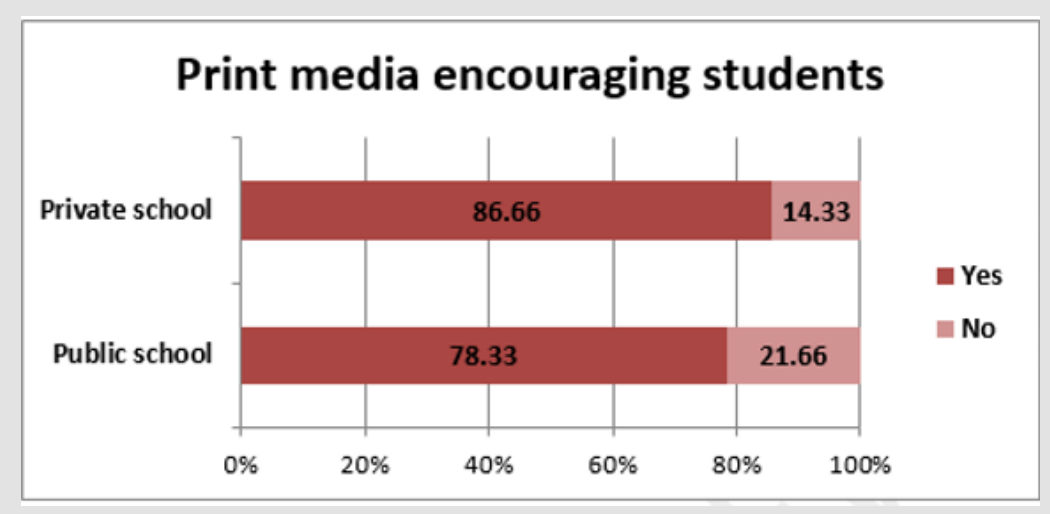

Figure 3: Distribution of student's response on the basis of print media encourage them.

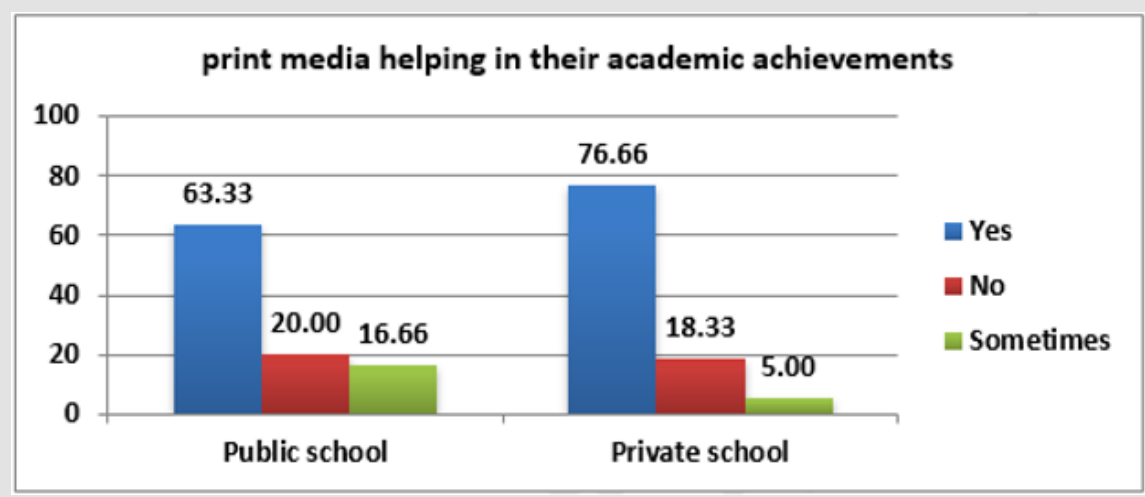

Figure 4: Distribution of response of students on sources of print media helps in their academic achievements. 
e) Print media helpful for students in academics performance: The role of print media sources encourages students to grow scientific, critical thinking, and to be creative with their work. It also helpful in develop critical and independent thinking in students and youths through their exposure to a wide variety of instructional resources and learning opportunities [13]. Data presented in above (Table 5) shows that less than half $(45.00 \%)$ of selected students from public school said that sources of print media was helpful in most of the cases of their academic performance, 21.00 percent of students said that in some cases it was useful, 20.00 percent students says that it was helpful in few cases of academics, 10.00 percent of students said very useful for them and at the same only 3.33 percent students said that print media sources not useful for them. In private school, 43.33 percent of students were said that in most of the cases print sources are useful for their academics, 28.33 percent said that in some cases it was useful, 16.66 percent students said that in very few cases it useful, 10.00 percent students said that these sources were very useful for their academic performance while only 1.66 percent students said that not really useful for their academics, they use it only for entertainment and other purpose Figure 5.

Table 5: Response of students on sources of print media help in their academic achievements.

\begin{tabular}{|c|c|c|}
\hline \multirow{2}{*}{ Response } & Public School & Private School \\
\cline { 2 - 3 } & $\mathbf{f ( \% )}$ & $\mathbf{f ~ ( \% )}$ \\
\hline Much useful & $6(10.00)$ & $6(10.00)$ \\
\hline Most of the cases & $27(45.00)$ & $26(43.33)$ \\
\hline Some cases & $13(21.66)$ & $17(28.33)$ \\
\hline Few cases & $12(20.00)$ & $10(16.66)$ \\
\hline Not useful & $2(3.33)$ & $1(1.66)$ \\
\hline
\end{tabular}

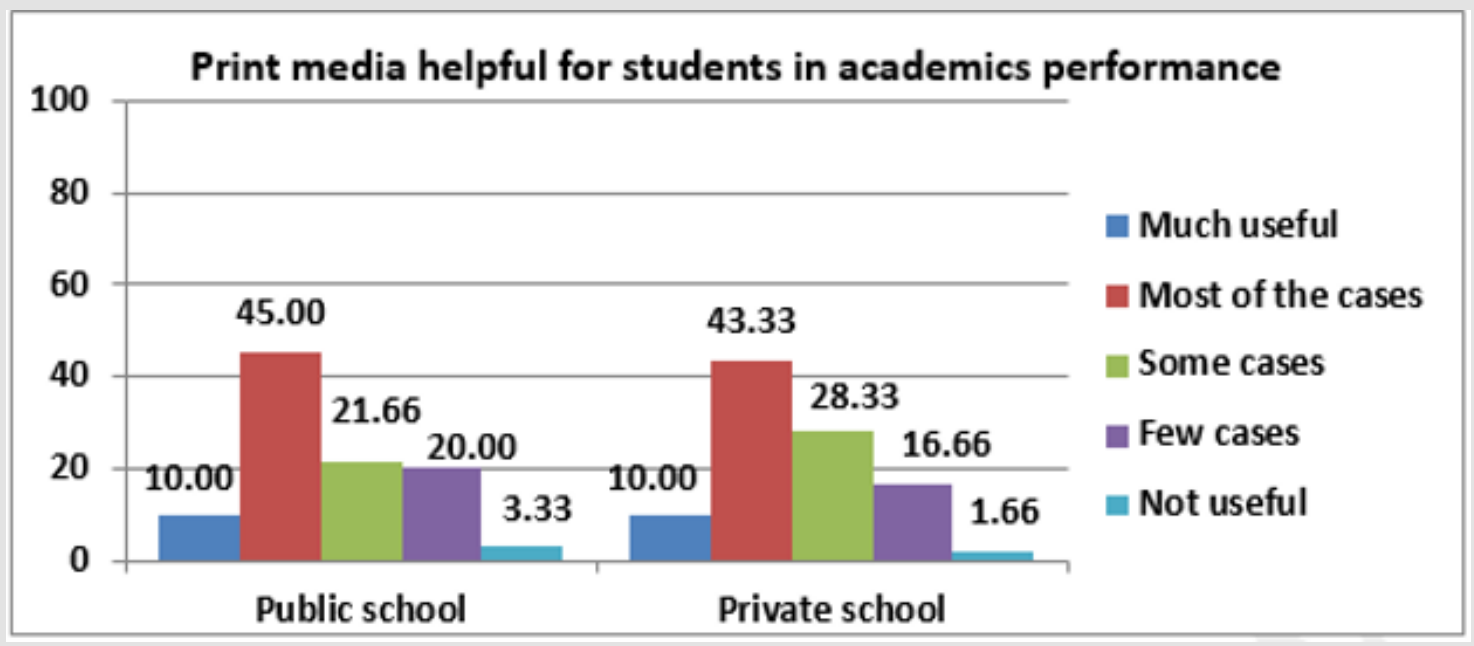

Figure 5: Graph presentation of response of students on sources of print media help in their academic achievements.

[14-16] found in her results that the newspapers were useful for adolescents because it was given the maximum coverage on educational issues, the reason for that being that in the months of May and June the results of class ten and class twelve of various boards are declared in India. This is also the time of admission to colleges and the schools are also to begin a new academic year. And Dorr and Rubin (1995) revealed in his results that mass media effects can be positive or negative. In this study, increase in media usage, (in terms of amount) is correlated with poorer school achievements, poorer social relationships, fewer school interactions and lower reading scores. However, several studies showed that increased usage of educational media has been shown to have beneficial effects. This is only a partial review of the effect's media have on students.

\section{Conclusion}

This study revealed a comprehensive diagram of contents in print media sources shows that all students were selected were used print media sources in different ways and types. These sources were also encourage most of the students to do something new with their school assignments which helps to improve their academic performance and also print media sources were very helpful for them in most of the cases of their academic activities. Print media are also encouraging students to use them as increase their vocabulary, easy available and pocket friendly for their parent. Students have to make use of print media sources in a positive manner like research purposes (searching good colleges for getting admission in future, different coaching classes, counselling, results and other), such as assignments, projects and other academic attempts. This shows that print media sources are not only used for entertainment but also for information and sstudents should use it smartly to improve their academic performance.

\section{References}

1. Arnett J (1995) 'Adolescents' uses of media for self-socialization.' Journal of Youth and Adolescence 5: 519-532. 
2. Dorr A, Robin B E (1995) Parents, Children, Television In: M. Bornstein (Ed.) Handbook on Parenting.

3. Gerbner G, Gross L, Morgan M, Signorielli N (1980) The "Mainstreaming" of America: Violence Profile No. 11. Journal of Communication 30(3): 10-29.

4. Goswami Ruchi, Kumari Manju (2013) Impact of Indian Cinema on Adolescents: A Sociological Study of Jaipur-Rajasthan. Int Res J Social Sci 2(7): 19-32.

5. Katz E, Blumler J, Gurevitch M (1979) Utilization of mass communication by the Individual. In J G Blumler \& E Katz Eds. The uses of mass communications: current perspectives on pratifications research, Beverly Hills \& London: Sage Publications 6(1): 9-36.

6. Mitra S (2015) MODULE -2 Notes Print Media Introduction to Print Media 5 introduction to print media.

7. Nair R (2003) Press Ki Aazadi, Aankh Micholi Ke 6 Dashak. Bhopal: Media Mimansa. Journal of Makhanlal Chaturvedi National University of Journalism and Communication 1 (3): 9-12.

8. Oduor A (2015) Mass Media and Education: Locating the Functions and Influence of Newspaper Model Examinations on KCPE Performance in Kenya (unpublished).

9. Rani Padma (2012) Media Perception of Adolescence: A Comparative Analysis of Adolescence Issues. In: The National Newspapers-The Times of India and The Hindu", 4th International Conference of Life Skills Education.

ISSN: 2574-1241

DOI: 10.26717/BJSTR.2021.33.005478

Salem Aboglila. Biomed J Sci \& Tech Res

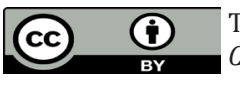

This work is licensed under Creative Commons Attribution 4.0 License

Submission Link: https://biomedres.us/submit-manuscript.php
10. Sudha Rani Y (2014) News Paper Reading Habits of Vikrama Simhapuri University Students: A study. Journal of Advances in Library and Information Science 3(2): 116-120.

11. Rao P S (2019) The role of newspapers and magazines to teach english in the esl/efl classrooms in the digital era: a comprehensive study. Jour Eng Lng \& Lit 6 (2): 165-173.

12. Shukla R (2010) The Economic Times Usage of mass media by youth, Mass media influences youth culture: it is an axiom that ingrained in the popular imagination over three generations since World War II.

13. Sridhar MS (1996) Beware of electronic media and libraries@ invited paper for 15th Annual Convention and Conference of Society for Information Science on 'Digital Libraries'. Indian Institute of Science, Bangalore.

14. The Times of India (March 29, 2018). Mobile internet users in India seen at 478 million by June: IAMAI

15. Swaminathan, K S M (2017) News Paper Reading Habits among the Students of Arts Colleges in Madurai, Tamil Nadu: A Study. Indian Jour Info Sources and Services (7) 1:36-39.

16. Srivastava V, Vaish B, Singh RP, Singh P (2020) An insight to municipal solid waste management of Varanasi city, India, and appraisal of vermicomposting as its efficient management approach. Environmental monitoring and assessment 192(3): 1-23.

$\begin{array}{ll}\text { BIOMEDICAL } & \text { Assets of Publishing with us } \\ \text { RESEARCHES } & \text { - Global archiving of articles } \\ \text { - Immediate, unrestricted online access } & \text { - Rigorous Peer Review Process } \\ & \text { - Authors Retain Copyrights } \\ \end{array}$

